\title{
Lack of hepatic c-Met and gp130 expression is associated with an impaired antibacterial response and higher lethality after bile duct ligation
}

\author{
Arne Giebeler ${ }^{1,2}$, Lars-Ove Brandenburg ${ }^{3}$, Michaela Kaldenbach ${ }^{1}$, Stephanie Erschfeld ${ }^{1}$, Hermann Wasmuth ${ }^{1}$, \\ Christoph Wruck ${ }^{3}$, Christian Trautwein ${ }^{1}$ and Konrad L Streetz ${ }^{1}$
}

The prognosis of liver failure is often determined by infectious and cholestatic complications. As HGF/c-Met and interleukin (IL)-6/gp130 control hepatic cytoprotective pathways, we here investigated their cooperative role during the onset of cholestatic liver injury. Conditional hepatocyte-specific $\left(^{\left({ }^{\text {hepa }}\right)}\right.$ c-Met, gp130 and c-Met/gp130 knockout mice (Cre-loxP system) were subjected to bile duct ligation (BDL) and lipopolysaccharide (LPS) stimulation. gp130 ${ }^{\Delta \text { hepa }}$ and c-Met/ gp $130^{\Delta \text { hepa }}$ mice displayed increased lethality associated with severe bacteraemia early after BDL, whereas c-Met ${ }^{\Delta \text { hepa }}$ and wild-type mice showed normal survival. Analysis of the innate immune response and the regulation of hepatic antibacterial pathways showed that the LPS-triggered hepatocellular response via the Toll-like receptor-4 pathway was regulated differentially by HGF/c-Met and IL-6/gp130. Activation of p38MAPK, c-Jun N-terminal kinase and signalling transducer and activator of transcription-3 was impaired in gp $130^{\Delta}$ and c-Met ${ }^{\text {Shepa }}$ livers. In addition, the acute-phase response (APR) was reduced in c-Met ${ }^{\text {Shepa }}$ livers, whereas gp $130^{\text {thepa }}$ displayed a completely abolished APR. In contrast, TNF- $\alpha$-dependent NF- $\kappa B$ activation was enhanced in gp $130^{\Delta \text { hepa }}$ and c-Met ${ }^{\Delta \text { hepa }}$ mice and it was associated with a higher rate of apoptosis and inflammation. Moreover, expression of the neutrophil produced and secreted cathelin-related antimicrobial peptide and of genes related to the inflammasome complex correlated with the strength of the bacterial infection and with TNF- $\alpha$ expression. In conclusion, Gp130 and c-Met are involved in the hepatic antibacterial and innate immune response, control the APR and thus prevent sepsis and liver injury during cholestatic conditions.

Laboratory Investigation (2012) 92, 1726-1737; doi:10.1038/labinvest.2012.122; published online 17 September 2012

KEYWORDS: acute-phase response; bile duct ligation; c-Met; gp130; innate immune response

Acute and chronic liver injury is often complicated by cholestatic episodes, which trigger metabolic or infectious complications independent of the underlying aetiology. This can ultimately result in severe disturbance of body homeostasis, disease progression or potentially lethal septic complications. ${ }^{1}$ Therefore, a better understanding of relevant organ-protecting mechanisms is helpful to improve the prognosis of the patients.

The innate hepatic antimicrobial host defence involves several mechanisms. First, microbial pathogens are recognized (bacterial recognition) via its surface molecules, eg, lipopolysaccharide (LPS; Gram-negative bacteria) through LPS-binding protein $(\mathrm{LBP})^{2}$ and its co-receptor CD14 ${ }^{3}-$ both forming a complex with Toll-like receptor 4 (TLR4). TLR4 activates a signalling cascade, involving TIRAP, ${ }^{4}$
${\mathrm{MyD} 88^{5}}^{5}$ and among others IRAK1/4 kinases ${ }^{6}$, which triggers activation of the innate hepatic immune response. This includes an increase in the expression of proinflammatory genes involved in recruiting white blood cells to the site of inflammation. Beside TLRs also intracellular pattern recognition factors, eg, NOD1 and $\mathrm{NOD} 2,{ }^{7}$ are important for the recognition of microbial elements and the initiation of the innate immune response. ${ }^{8}$ In turn the formation of the inflammasome is triggered by a wide range of pathogen- and host-derived 'danger' signals. Additional protective mechanisms are provided through the secretion of antimicrobial peptides (AMPs), such as cathelicidins by neutrophils ${ }^{9}$ and the activation of the acute-phase response (APR) is through interleukin (IL)-6/gp130-dependent signals. ${ }^{10}$

\footnotetext{
'Department of Medicine III, University Hospital, Aachen, Germany; ${ }^{2}$ Department of Surgery, University Hospital, Aachen, Germany and ${ }^{3}$ Department of Anatomy and Cell Biology, Medical Faculty, RWTH Aachen University, Aachen, Germany

Correspondence: Dr KL Streetz, Departmentt of Medicine III, University Hospital, RWTH Aachen, Pauwelsstreet 30, 52074 Aachen, Germany.

E-mail: kstreetz@ukaachen.de

Received 29 December 2011; revised 1 June 2012; accepted 12 June 2012
} 
Essential factors for maintaining liver cell integrity and controlling liver regeneration are cytokines (IL-6, TNF- $\alpha$ and TGF- $\beta$ ) and growth factors (HGF, EGF and KGF). Here, we focused on the HGF receptor tyrosine kinase c-Met and the IL-6 signalling transducer gp130, which have important roles in the maintenance of liver organ homeostasis.

Gp130 is the key receptor regulating the APR and is essential for the induction of the $S A A$ gene family via signalling transducer and activator of transcription-3 (STAT3), ${ }^{11}$ which helps to defeat bacterial infections in mice. ${ }^{12}$ Further analysis demonstrated gp130 as an important modulator of cell cycle induction after liver injury. ${ }^{13} \mathrm{C}$-Met is one of the most important factors for the initiation of cellular proliferation in quiescent hepatocytes and during liver regeneration ${ }^{14}$ and in preventing liver fibrogenesis. ${ }^{15}$

As both receptor systems were shown to mediate regenerative, anti-fibrotic and immunoprotective functions, we hypothesised that they may act synergistically hepatoprotective. Potential cooperative mechanisms initiated by either pathway with special focus on antimicrobial defence mechanisms were therefore investigated in a model of experimentally induced cholestasis.

\section{MATERIALS AND METHODS Generation of Hepatocyte-Specific c-Met and gp130 Knockout Mice}

The generation of functional hepatocyte-specific c-Met $\left(\mathrm{c}-\mathrm{Met}^{\Delta \text { hepa }}\right)^{16}$ and gp130 (gp130 $\left.{ }^{\Delta \text { hepa }}\right)$ knockout mice was described before. ${ }^{17}$ Viable c-Met ${ }^{\Delta \text { hepa }}$ offspring carrying a postnatal active albumin-Cre promoter construct were crossbreaded with gp130 loxP/loxP mice to obtain c-Met/gp130 double conditional knockout mice. C-Met/gp130 offspring were then born with a normal Mendelian frequency. Cre and loxP status were analysed by PCR using a Ready-Taq system (Sigma-Aldrich, Steinheim, Germany).

\section{Bile Duct Ligation (BDL)}

Eight- to ten-week-old C57/B6 mice $(\mathrm{Cre}(-)$ and $\mathrm{Cre}(+)$ c-Met ${ }^{\text {loxp/loxP }}$ mice) were subjected to BDL for up to 4 weeks. BDL was performed by tying the common bile duct using a non absorbable filament (Ethicon, Boston, MA, USA). For each of the following analysis at least four mice per time point were investigated. All experiments were performed at least twice.

\section{Evaluation of Statistical Significance}

All significant $P$-values were calculated and proven via Student's $t$-test.

\section{Immunoblotting}

For the detection of phosphorylated STAT3 liver nuclear extracts were prepared. Cytoplasmic protein of $50 \mu \mathrm{g}$ was loaded on a $10 \%$ SDS-PAGE and run for $1.5 \mathrm{~h}$. The proteins were transferred to a PVDF membrane using a wet blotting system (Bio-Rad, Munich, Germany). Next, the membrane was blocked in TBS-T containing 5\% dry milk powder. The anti-phospho STAT3, anti-phospho p65, anti phospho c-Jun N-terminal kinase (JNK)1/2, JNK1/2, anti-phospho p38, p38 antibody, anti-ERK1/2, anti IRAK4 (Cell Signalling/NEB, Frankfurt/Main, Germany), TRAF6 (Santa Cruz, Heidelberg, Germany), MyD88 (eBioscience, Frankfurt/Main, Germany) and GAPDH (Abd Serotec, Duesseldorf, Germany) were incubated over night at $4{ }^{\circ} \mathrm{C}$ according to the manufacturer's instructions. For detection and visualization (LAS-3000 System, FujiFilm, Germany) a secondary horseradish peroxidase-conjugated antibody (Cell Signalling or Santa Cruz) and ECL solution (Pierce, Bonn, Germany) were used.

\section{Immunofluorescent Stainings}

Cryopreserved liver tissue was cut in $5-\mu \mathrm{m}$ sections. Neutrophils were stained using a rat anti-mouse Ly6G antibody (BD Bioscience, Heidelberg, Germany). The antibody was incubated for $1 \mathrm{~h}$ at room temperature in $1 \%$ mouse serum dissolved in PBS (PAA, Vienna, Austria) containing 0.02\% sodium acetate (Sigma-Aldrich). Cathelin-related antimicrobial peptide (CRAMP) was detected using an antiCRAMP antibody (Santa Cruz) and an Alexa 594 secondary antibody (Molecular Probes/Invitrogen, Karlsruhe, Germany). Detection of Ly6G was performed using an Alexa 488 secondary antibody (Molecular Probes/Invitrogen). Ki67 antibody was purchased from (Dako, Hamburg, Germany) and counterstained using an Alexa 488-conjungated secondary antibody.

DNA strand breaks were detected using the TUNEL detection Kit (Roche, Mannheim, Germany). Nuclei were counterstained with DAPI (Vector Laboratories/Axxora, Loerrach). Immunofluorescent signals were detected using an AxioImager Z1 microscope (Carl Zeiss, Jena, Germany). Images were taken in a $\times 200$ magnification.

\section{Histology}

Liver samples were fixed in 3.5\% formaldehyde, embedded in paraffin and cut $2-3 \mu \mathrm{m}$ strong. The sections were incubated for 5 min in haematoxylin according to Mayer (Roth, Karlsruhe, Germany). After washing with hand warm water, eosin (Roth) treatment was followed for $1 \mathrm{~min}$, slides were rinsed and dehydrated in an increasing ethanol row and finished in Roti-Histol (Roth). Slides were mounted by using RotiHistokit (Roth). Pictures were taken $(\times 100$ magnification) using the brightfield option of the Axio-Imager Z1 (Carl Zeiss).

For assignation of necrotic areas sections were counted. A minimum of five view fields per tissue/mouse was counted for each time point per genotype.

\section{Gene Expression Analysis by Real-Time PCR}

Total RNA was extracted from cryopreserved liver tissue by using peqGold RNAPure ${ }^{\mathrm{TM}}$ (PeqLab, Erlangen, Germany). After isolation $500 \mathrm{ng}$ of total RNA were transcribed into cDNA by using the RT Omniscript Kit (Qiagen, Hilden, Germany). The detection of cDNA expression for specific genes was performed by using the Sybr ${ }^{\mathbb{R}}$ GreenER $^{\mathrm{TM}}$ qPCR 
Supermix (Invitrogen). Primer sequences are available on request. Analysis was performed as recommend by the manufacturer. In the case of primary hepatocytes, cells were lysed in RLT buffer (Qiagen) and RNA was isolated using the RNeasy Mini Kit (Qiagen) according to the manufacturer's instructions.

\section{Isolation of Hepatocytes}

For isolation of hepatocytes, the mouse livers were perfused with buffer $(153 \mathrm{mM} \mathrm{NaCl}, 5.6 \mathrm{mM} \mathrm{KCl}, 5 \mathrm{mM}$ glucose, $20 \mathrm{mM}$ HEPES and $25 \mathrm{mM} \mathrm{NaHCO}$ ), spiked with $1 \mathrm{mM}$ EDTA, $5 \mathrm{mM} \mathrm{CaCl}_{2}$ and $10 \mathrm{mg}$ collagenase. The solution was preheated at $37^{\circ} \mathrm{C}$ and the lower vena cava was cannulated using a catheter court 20G (VYGON, Aachen, Germany). The bleached and perfused liver was transferred into DMEM media containing 10\% FCS and disrupted manually. The resulting suspension was filtered, liver cells were separated and washed twice by centrifugation (Kendro-Haraeus, Hanau, Germany) at $16 \mathrm{~g} 4 \mathrm{~min} 4{ }^{\circ} \mathrm{C}$. Primary hepatocytes were plated on collagen-coated six-well plates and supplemented with DMEM containing 10\% FCS for overnight settlement.

\section{LPS Stimulation In Vivo and In Vitro}

To investigate the LPS response in vivo mice received an intraperitoneal injection of $10 \mu \mathrm{g}$ LPS (Sigma Aldrich) dissolved in PBS (pH 7.4; PAA, Cologne, Germany). After $6 \mathrm{~h}$, the mice were killed, blood samples were taken; the liver was resected and cryopreserved for further analysis. After overnight incubation, primary hepatocytes were stimulated with $10 \mu \mathrm{g}$ LPS for $6 \mathrm{~h}$. To isolate RNA for gene expression analysis cells were lysed using RLT buffer from the RNeasy Mini Kit (Qiagen). Untreated cells were used as controls.

\section{RESULTS}

\section{Enhanced Mortality of Mice Lacking Hepatic gp130 Activation During the Early Phase After BDL}

Transgenic mouse strains carrying hepatocyte-specific deletions of c-Met $\left(\mathrm{c}-\mathrm{Met}^{\Delta \text { hepa }}\right)$, gp130 $\left(\mathrm{gp} 130^{\text {hepa }}\right)$ or both (c-Met/gp130 $0^{\Delta \text { hepa }}$ ) and their respective controls (c-Met/ gp $\left.130^{\Delta \operatorname{loxP} / \text { loxP }}\right)$ were subjected to BDL. Interestingly, c-Met/ gp130 ${ }^{\Delta \text { hepa }}$ and gp $130^{\Delta \text { hepa }}$ mice showed enhanced mortality rates already $2\left(\mathrm{c}-\right.$ Met/gp $\left.130^{\Delta \text { hepa }}\right)$ and $4\left(\mathrm{gp} 130^{\Delta \text { hepa }}\right)$ days after BDL whereas c-Met ${ }^{\Delta \text { hepa }}$ and control mice survived the critical early phase after BDL (Figure 1a). Overall survival 7 days after BDL was $37.5 \%$ in gp $130^{\text {Ahepa }}, 50 \%$ in c-Met/ gp $130^{\Delta \text { hepa }}$ vs $100 \%$ in controls and c-Met-deleted mice. During a longer observation period (up to 4 weeks) control mice survived indefinitely, c-Met ${ }^{\Delta \text { hepa }}$ displayed $87.5 \%$ survival, while in both groups with gp130 deletion only $20 \%$ long-term survivors were evident.

Histological liver analysis unravelled more necrotic areas and tissue injury in mice with a hepatocyte-specific deletion of c-Met, gp130 or both in comparison with control mice (Figures $1 \mathrm{~b}$ and $\mathrm{c}$ ). The largest number of necrotic areas was observed in livers of c-Met/gp130 13 hepa mice $(11 \pm 3$ as compared with 2.4 in controls, $P<0.001$ ), which might be due to their inability to compensate the onset of cholestatic liver injury. Transaminases were increased in either genotype with no significant differences among subgroups (data not displayed).

\section{Inflammation and Apoptosis Rates Correlate with Cholestatic Liver Injury}

After BDL, the numbers of liver infiltrating mononuclear cells in mice of all groups increased significantly $(P<0.01)$. The majority of infiltrating cells (Figure 1d, Supplementary Figure 1a) could be identified as neutrophils. The highest cell numbers were found in $\mathrm{c}-\mathrm{Met}^{\Delta \text { hepa }}$ and c-Met/gp130 ${ }^{\Delta \text { hepa }}$ mice, roughly correlating to the size of necrotic areas. TUNEL staining evidenced that the number of apoptotic cells increased significantly in $\mathrm{c}-\mathrm{Met}^{\mathrm{thepa}}$ mice compared with controls and an even stronger increase in TUNEL-positive cells was observed in c-Met/gp130 $0^{\text {hhepa }}$ mice (Figure 1e, Supplementary Figure 1b). This is supported by prior findings showing a higher sensitivity of c-Met-deficient hepatocytes during liver injury. ${ }^{15}$

Compensatory cell proliferation in bile duct-ligated livers was analysed by Ki67 staining (Figure 2a, Supplementary Figure 1c). The numbers of proliferating cells substantially increased (approximately fourfold) in c-Met/gp130 $0^{\operatorname{lox} P / \operatorname{loxP}}$ and gp $130^{\Delta \text { hepa }}$ livers, whereas c-Met ${ }^{\Delta \text { hepa }}$ and c-Met/gp $130^{\Delta \text { hepa }}$ mice displayed a smaller increase in proliferation rates $(\sim 1.8$ fold). To determine the contribution of bile ducts during the hepatic regenerative approach, we additionally analysed the proliferation of biliary epithelial cells after BDL (Figures $2 \mathrm{~b}$ and c). Here, we can show an increasing proportion of CK19/ Ki67 $(+)$ cells $\left(c-M e t / g p 130^{\text {loxP/loxP }}<\right.$ c-Met $^{\Delta \text { hepa }}<$ gp $130^{\Delta \text { he- }}$ $\mathrm{pa}<\mathrm{c}-\mathrm{Met} / \mathrm{gp} 130 \Delta \mathrm{hepa})$. This underlines that also the proliferation of biliary epithelial cells was correlated to the higher degree of liver injury in conditional knockout mice, interestingly being strongest in double-knockout mice.

\section{Bile Duct-Ligated Mice Show an Enhanced Bacterial Load}

BDL is known to trigger translocation of intestinal bacteria into the blood. ${ }^{1,17}$ Therefore, we tested the hypothesis whether differences in the bacterial load might explain the observed phenotype between the groups after BDL. Bacterial colony-forming unit (CFU) assays were performed from blood and homogenised liver tissue of bile duct-ligated mice. C-Met/gp130 ${ }^{\text {loxP/loxP }}$ showed almost no detectable bacterial translocation $\left(4.25 \pm 4 \times 10^{3}\right.$ c.f.u. $)$. In contrast, gp $130^{\Delta \text { hepa }}$ and especially c-Met ${ }^{\text {Ahepa }}$ mice displayed an already threefold increased amount of bacterial CFUs $\left(15 \pm 3 \times 10^{3}\right)$ in the blood $(P<0.05)$. Interestingly, c-Met/gp130 $30^{\Delta \text { hepa }}$ mice showed an $>20$-fold $\left(99 \pm 31 \times 10^{3}\right)$ higher number of CFUs in the blood compared with controls $(P<0.01)$. A strong increase of bacterial counts was found in livers of c-Met ${ }^{\Delta \text { hepa }}\left(40 \pm 10\right.$ c.f.u. vs $10 \pm 2$ gp $\left.130^{\Delta \text { hepa }}\right)$ and 


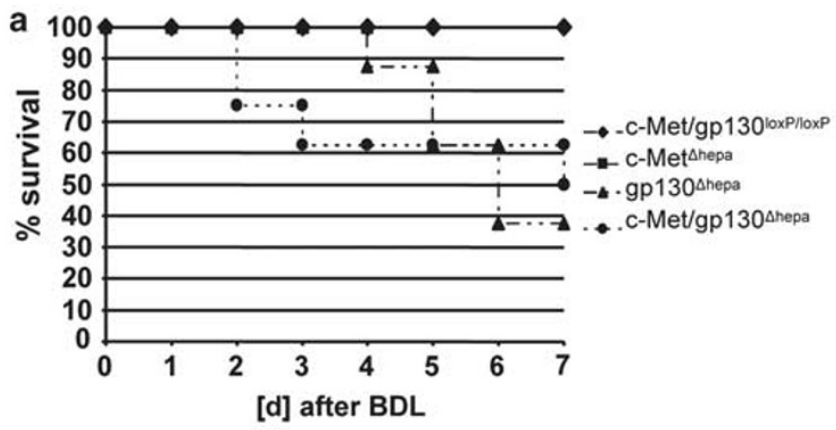

b
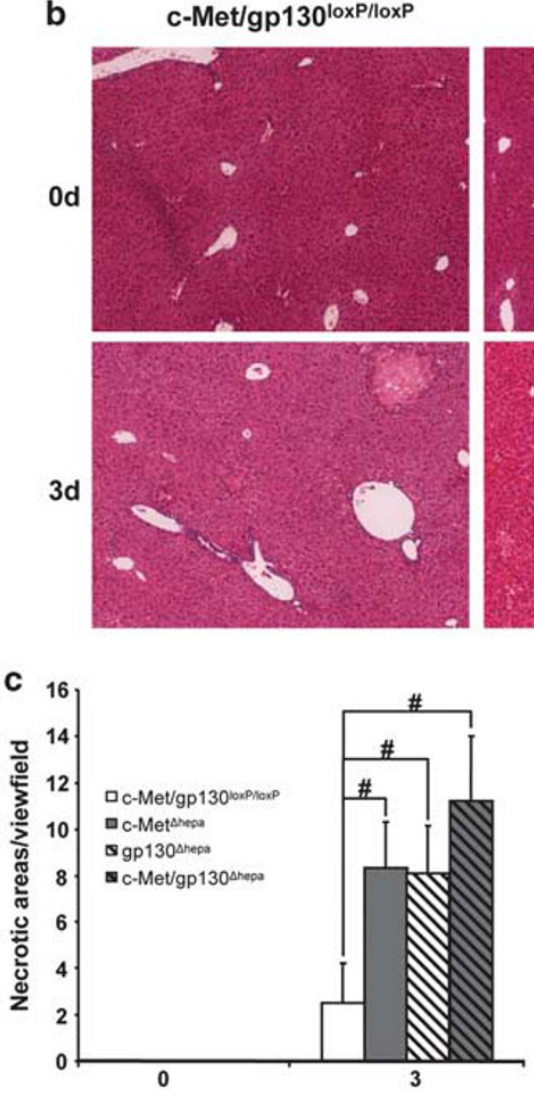

[d] after BDL
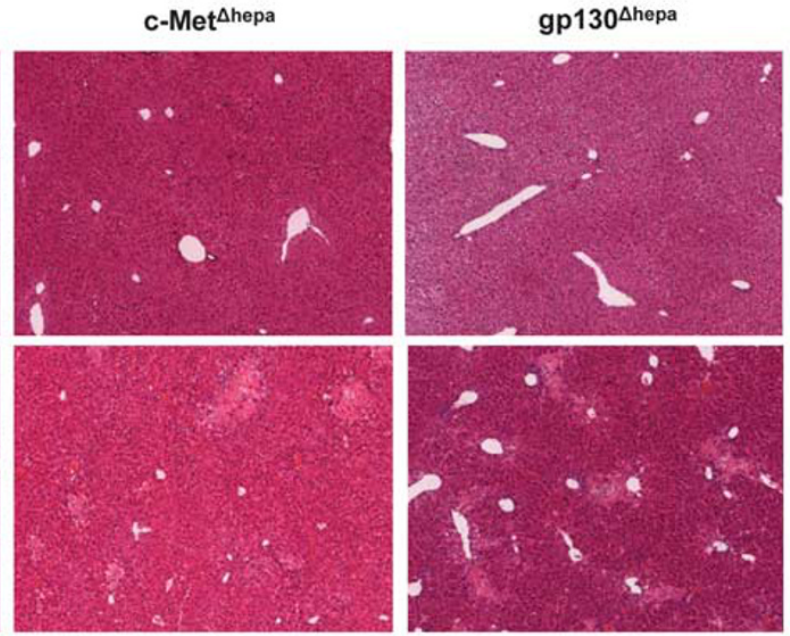

d

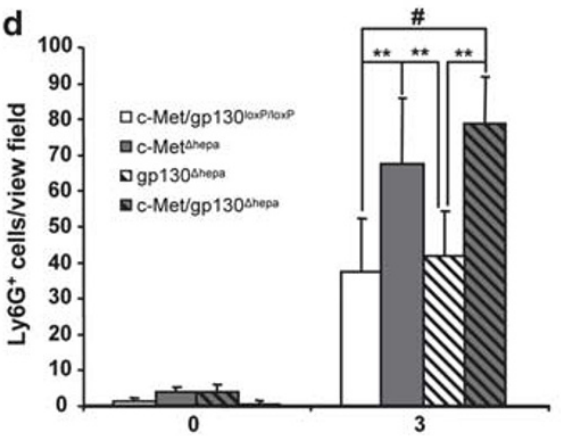

[d] after BDL

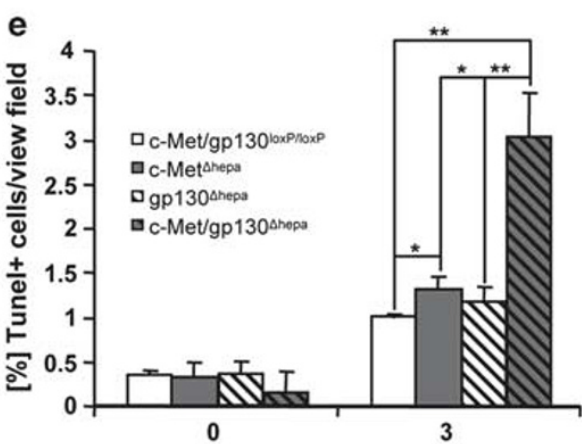

[d] after BDL

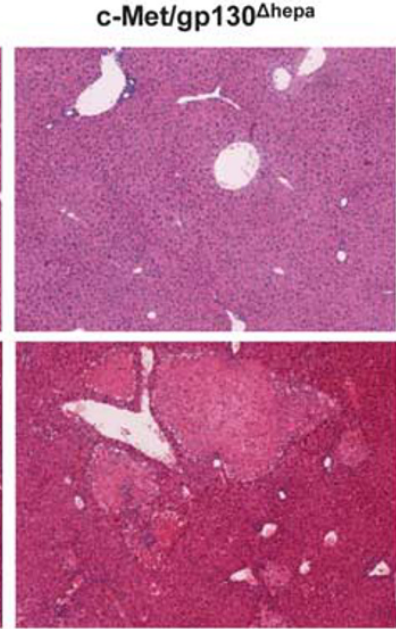

Figure 1 Analysis of survival and cellular damage after BDL. Survival of different mouse genotypes after BDL is displayed as a Kaplan-Meier curve (a). A histological analysis of liver injury is shown as representative histological H\&E stainings (b). The observed bile infarcts are displayed in 100 -fold magnification and analysed morphometrically according to their size (c). A tabulation of the quantitative neutrophil analysis by counting 10 viewfields/genotype/time point is shown in panel (d). A statistical scoring of the apoptotic cell in the TUNEL assay is shown in $(\mathbf{e}) .{ }^{*} P<0.05 ;{ }^{*} P<0.01$; and ${ }^{\#} P<0.001$.

c-Met/gp130 ${ }^{\text {hepa }}\left(182 \pm 60 \times 10^{3}\right)$ mice whereas controls showed no significant CFUs (Figures $3 \mathrm{a}$ and $\mathrm{b}$ ).

\section{c-Met and gp130 Regulate Molecules Involved in the Hepatic Bacterial Recognition After BDL}

In mammals, the unspecific antibacterial response consists of the classical bacterial recognition leading to the activation of the TLR4 pathway, the induction of AMPs and the activation of the inflammasome network.

The occurrence of an enhanced bacterial infiltration thus directed us to investigate those mechanisms in more detail.
Real-time PCR analysis unravelled a 4.5-fold increased expression of LBP mRNA in livers of c-Met ${ }^{\text {Ahepa }}$ mice, whereas c-Met/ gp130 $0^{\text {loxP/loxP }}$, gp $130^{\Delta \text { hepa }}$ and c-Met/gp130 ${ }^{\Delta \text { hepa }}$ mice displayed only a twofold increase (Figure 3c). Analysis of its co-receptor CD14 showed a significantly lower expression in a c-Metdependent manner. c-Met ${ }^{\Delta \text { hepa }}$ and c-Met/gp130 ${ }^{\Delta \text { hepa }}$ mice compared with mice with an active c-Met signalling pathway (Figure 3d). This is in concordance with our previously conducted gene array analysis (Supplementary Table 1). ${ }^{15}$

A next step in the innate immune response defending bacterial infections is the secretion of AMPs by infiltrating 

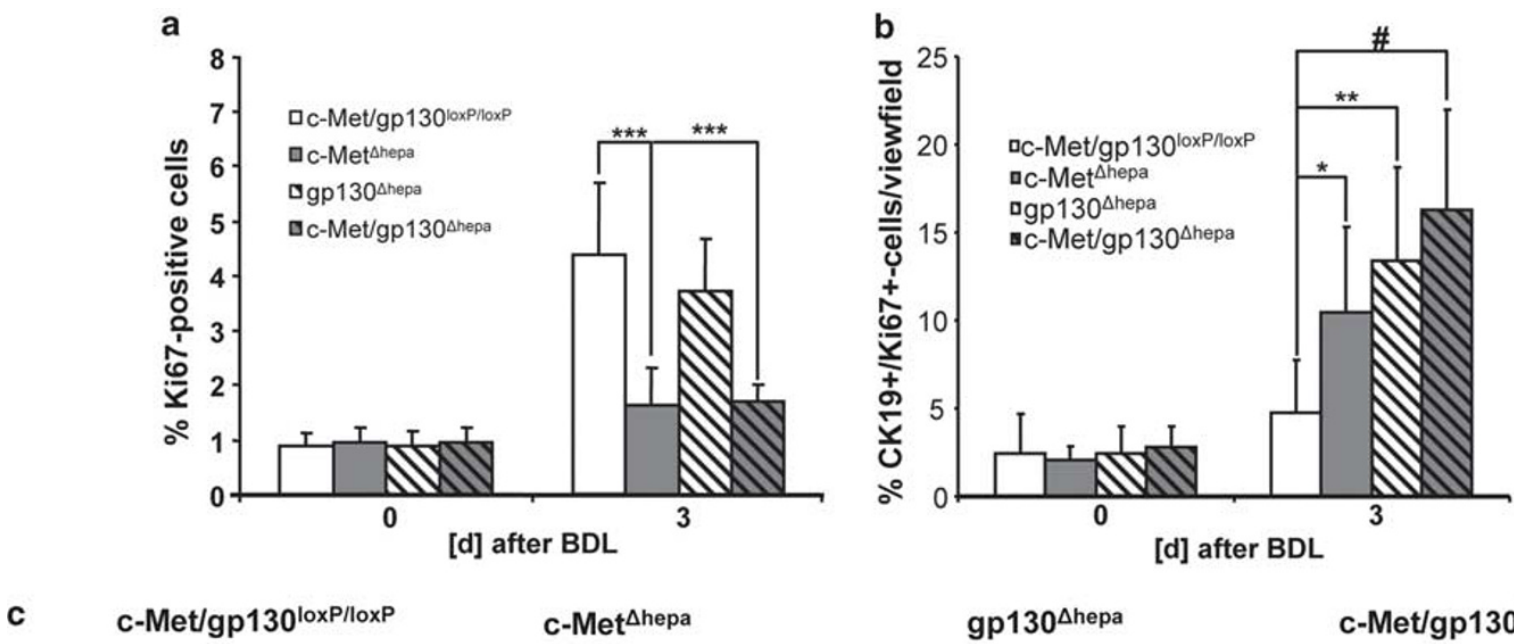

gp130 13 hepa

C-Met/gp130 13 hepa
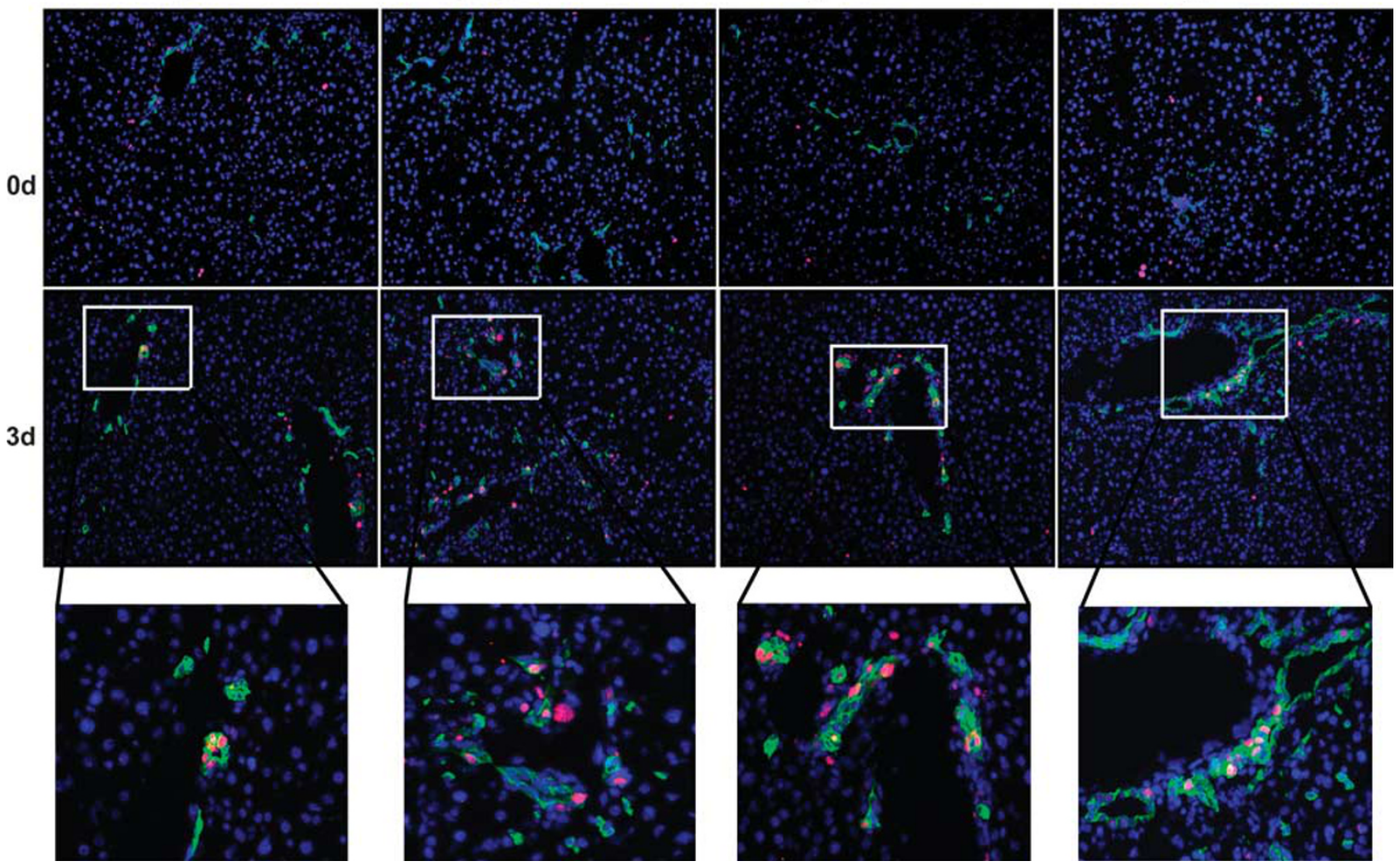

Figure 2 Cell proliferation analysis. First, overall cell proliferation was determined by staining Ki67 in cryopreserved tissue 0 day and 3 day post bile duct ligation. A quantitative analysis is given in panel (a). To further distinguish biliary epithelial cells, double stainings using CK19 as a marker for biliary cells and Ki67 as a marker for cell proliferation were performed. CK19-positive cells are shown in green (Alexa488 ${ }^{\mathbb{R}}$ ) and Ki67 was stained in red (Alexa594 ${ }^{\circledR}$ ), nuclei were counterstained using DAPI (b). The visual quantification of CK19/Ki67-double-positive cells in 12 high-power fields/time point and genotype are shown in panel (c). The proliferative activity in biliary epithelial cells is shown as a percentage ratio of $\mathrm{CK} 19^{+} / \mathrm{Ki} 67^{+}$-double-positive cells to total $\mathrm{CK} 19^{+}$cells per viewfield. ${ }^{*} P<0.05 ;{ }^{* *} P<0.01$; and ${ }^{\#} P<0.001$.

neutrophils. ${ }^{9}$ Hence, we analysed the expression of CRAMP_one of the best described AMPs—via real-time PCR. The most significant induction was observed in liver tissue of c-Met/gp130 1 hepa mice-the group with the highest bacterial load (Figure 3e). This expression pattern is further correlated to the number of infiltrating neutrophils (Figure 1d), which are known as the primary source for CRAMP. By using immunohistochemical double staining we were able to co-localise CRAMP expression on neutrophils (Figure 3f). Interestingly, we observed a significant induction of CRAMP expression directly in isolated primary hepatocytes (Supplementary Figure 2a), with absolute levels being much lower than in immune cells. 

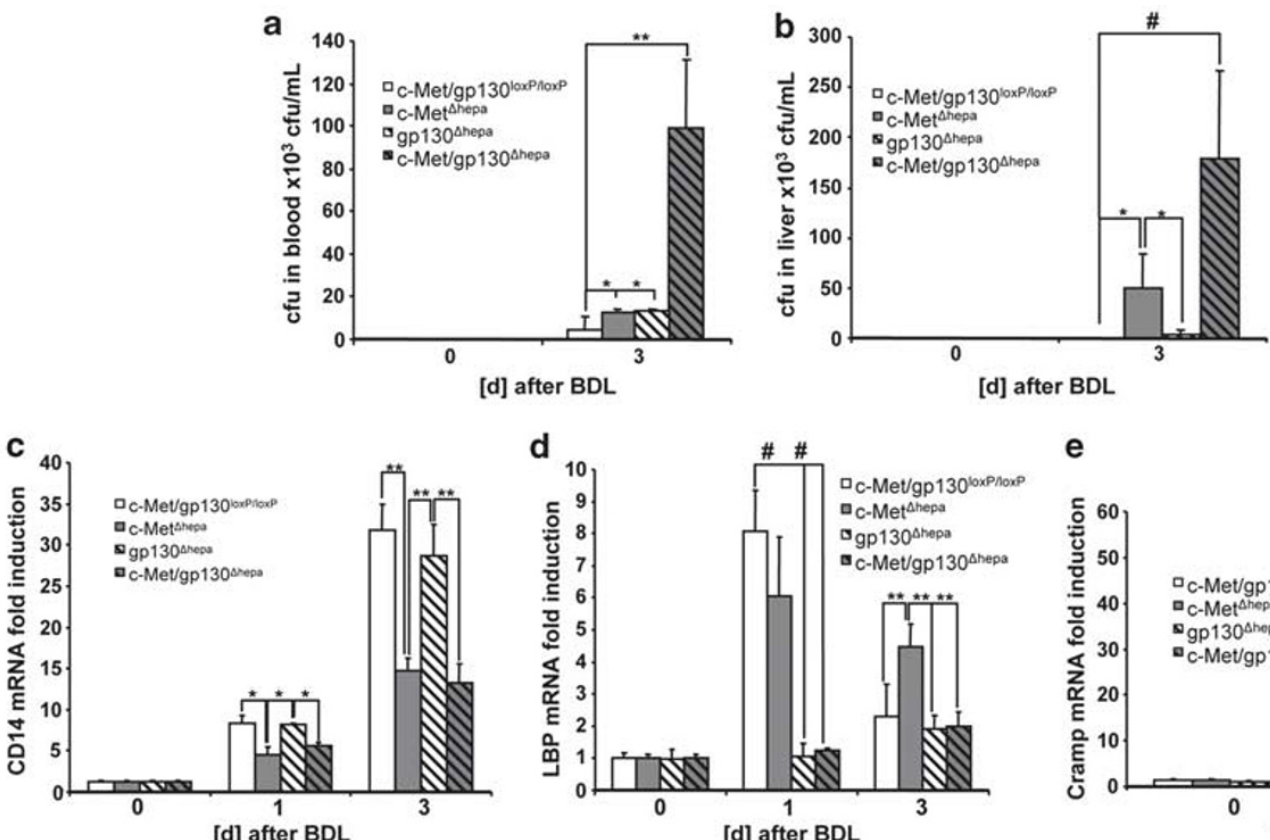

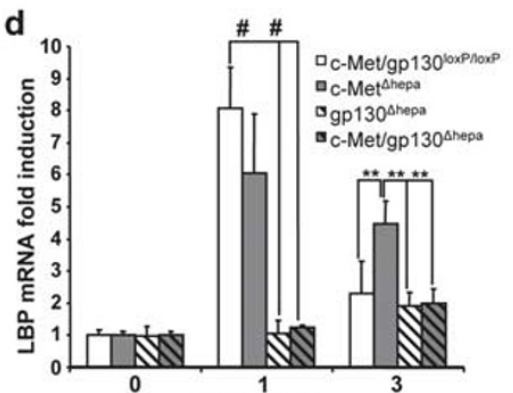

[d] after BDL

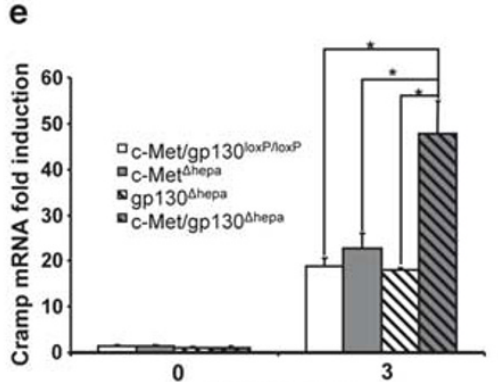

[d] after BDL

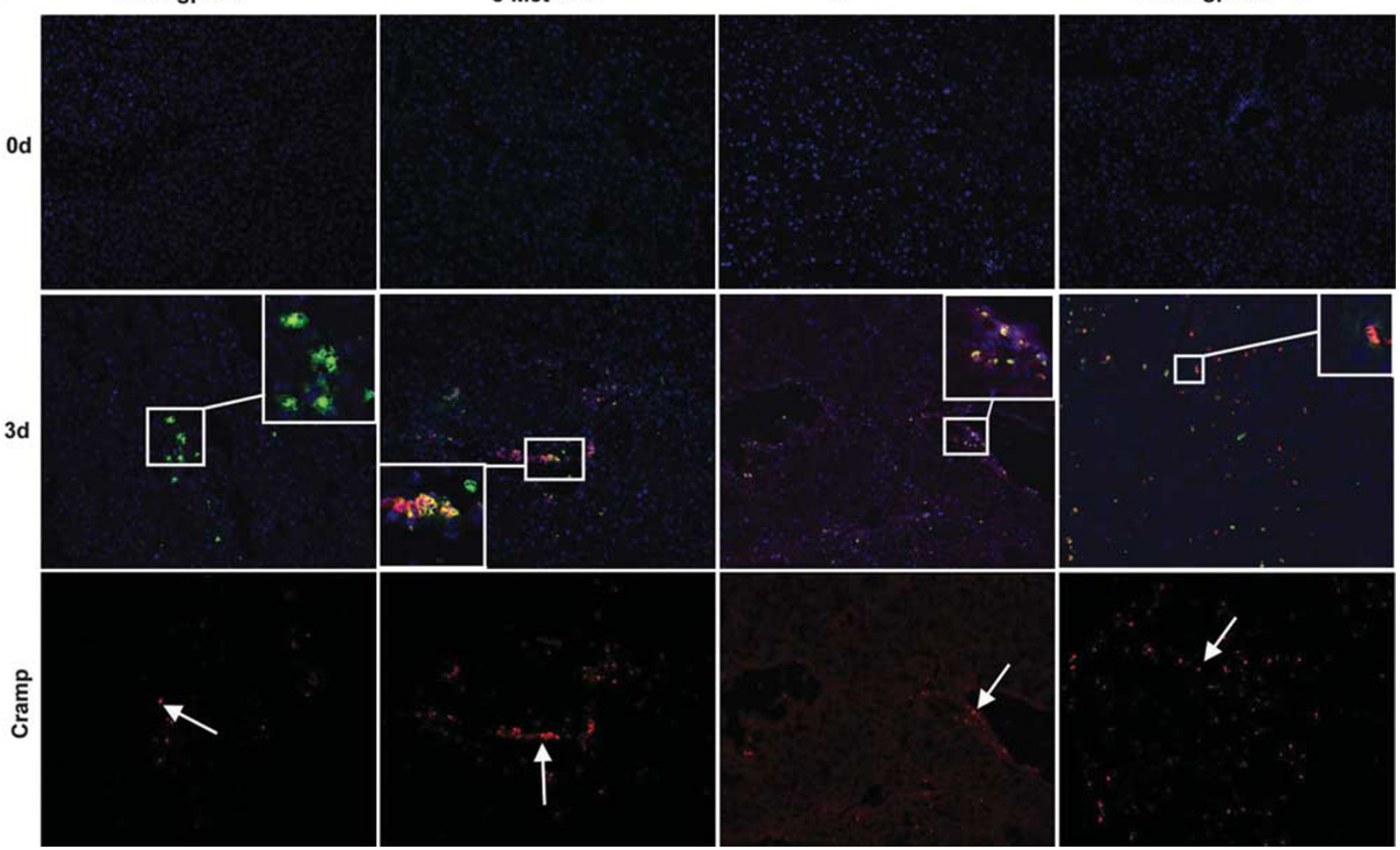

Figure 3 Bacterial load, recognition and CRAMP expression. The bacterial load in blood and livers of bile duct-ligated mice was determined by CFU assays of c-Met ${ }^{\Delta \text { hepa }}$, gp $130^{\Delta \text { hepa }}$ and c-Met/gp $130^{\Delta \text { hepa }}$ mice in comparison with c-Met/gp $130^{\text {loxP/loxP }}$ mice (a, b). The assay was performed in up to 10 individual mice per genotype. Displayed are real-time PCR analysis of the bacterial recognition genes LBP (c) and CD14 performed 1 and 3 days after $\mathrm{BDL}$ (d). ${ }^{*} P<0.05$; ${ }^{* *} P<0.01$; and ${ }^{\#} P<0.001$. Further displayed is a gene expression analysis of the anti-microbial peptide CRAMP 3 days (e) after BDL by using real-time PCR. Neutrophils were stained in liver sections by Ly6G (Alexa488 ${ }^{\circledR}$ green). The AMP CRAMP was visualized by using an anti-CRAMP antibody (Alexa594 ${ }^{\circledR}$ red, $\times 40$ ). Nuclei were counterstained with DAPI (f). 


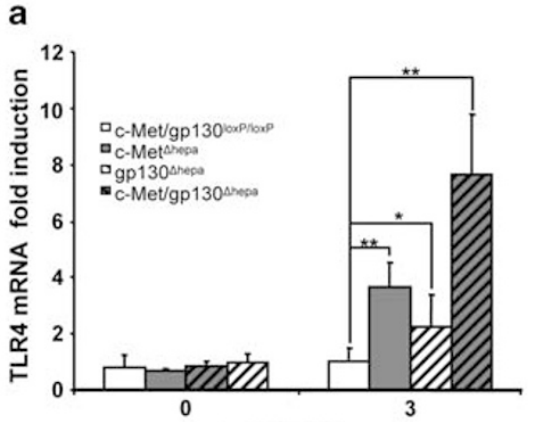

[d] after BDL

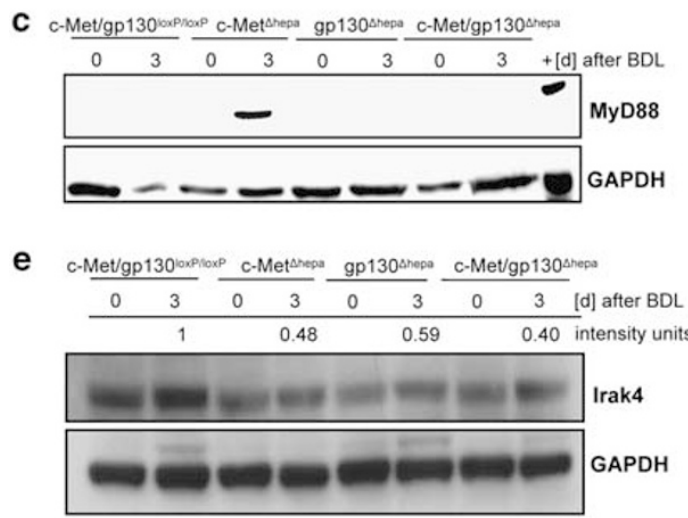

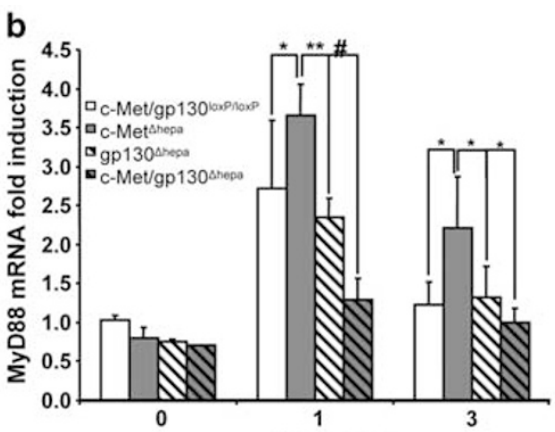

[d] after BDL

d

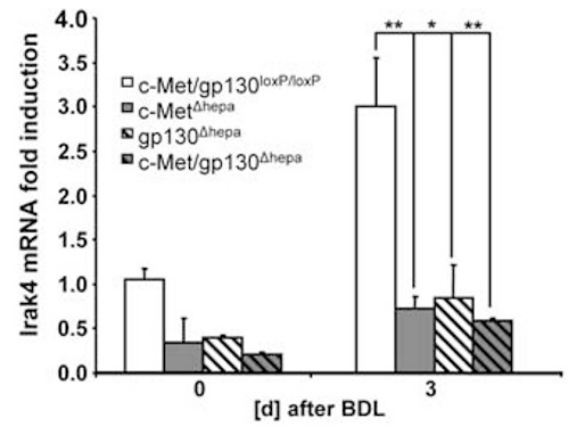

Figure 4 TLR4 and dependent signalling components. TLR4 and components of dependent signalling pathways were analysed by real-time PCR and western blot. Results of the gene expression analysis are shown for TLR4 (a), MyD88 (b), IRAK4 (d). Western blot analysis (c) of MyD88 and IRAK4 (e) 3 days after BDL (whole-liver extracts) displayed similar expression pattern as the by real-time PCR. GAPDH was used as a control to validate equal amounts of protein loading. ( ${ }^{*} P<0.05 ;{ }^{*} P<0.01$; and $\left.{ }^{\#} P<0.001\right)$.

To complete the analysis of the pathogen recognition network important intracellular components of the antibacterial defence were analysed after BDL. NOD-1 mRNA was 2.5-fold induced in c-Met/gp130 $0^{\operatorname{loxP} / \operatorname{loxp}}$ and further enhanced (fourfold) in c-Met ${ }^{\Delta \text { hepa }}$ mice. Interestingly, no induction was detectable in mice lacking hepatic gp130 (Supplementary Figure 2b). Ncf4 mRNA (Supplementary Figure 2c) was most significantly induced in c-Met/ gp $130^{\Delta \text { hepa }}$ mice. The consecutive investigation of Nod-like receptor-3 (Nlrp3) as part of the inflammasome complex unravelled the highest expression in c-Met ${ }^{\Delta \text { hepa }}$ and c-Met/ gp $130^{\text {Ahepa }}$ mice (Supplementary Figure $2 \mathrm{~d}$ ). Thus, the induction of the Nlrp3 gene correlated with the detectable level of bacterial colonies after BDL.

\section{Hepatocyte-Specific gp130 Deletion Changes the Expression of Genes Involved in the TLR4/MyD88 Pathway}

As TLR4 is a key component of the innate immune systemwhich gets activated during bacteraemia-we analysed its functionality to ensure the relevance of this pathway. Realtime PCR analysis displayed a significantly higher induction of TLR4 gene expression in livers of c-Met ${ }^{\Delta \text { hepa }}$ and c-Met/ gp $130^{\Delta \text { hepa }}$ compared with gp $130^{\Delta \text { hepa }}$ and c-Met/gp130 loxP/ loxP mice (Figure 4a). This correlates with the number of detectable hepatic CFUs after BDL. TLR4 signalling is mediated via the adapter molecule TIRAP for TLR4-specific signalling and/or via MyD88, which is known to integrate further signals triggered via the IL-1 receptor. MyD88 mRNA expression after BDL was specifically induced in c-Met ${ }^{\text {thepa }}$ mice (Figure 4b), a finding that could be supported by western blot analysis (Figure 4c). IRAK4 gene expression, however, was only induced in c-Met/gp $130^{\operatorname{loxP} / \text { loxP }}$ mice (Figures $4 \mathrm{~d}$ and e), as proven by qRT-PCR and western blot analysis. The gene expression of TIRAP, the second transducer molecule was similarly induced in control mice, whereas c-Met ${ }^{\Delta \text { hepa }}$, gp $130^{\Delta \text { hepa }}$ and c-Met/gp $130^{\Delta \text { hepa }}$ mice showed no induction of TIRAP gene expression (Supplementary Figure 3f). To possibly decipher cholestasismediated effects from infection-triggered signalling mechanisms, we challenged mice with LPS. This analysis showed a similar gene expression pattern for members of the antibacterial response (LBP, CD14, TLR4, MyD88 and TIRAP) as seen after BDL (Supplementary Figures 3a-e).

\section{Hepatic c-Met and gp130 Deficiency Enhances the Inflammatory and Hampers the Anti-Inflammatory Response in Mice}

As a response to injury, the liver produces cytokines to recruit immune cells to the origin of inflammation. ${ }^{18,19}$ First, the 


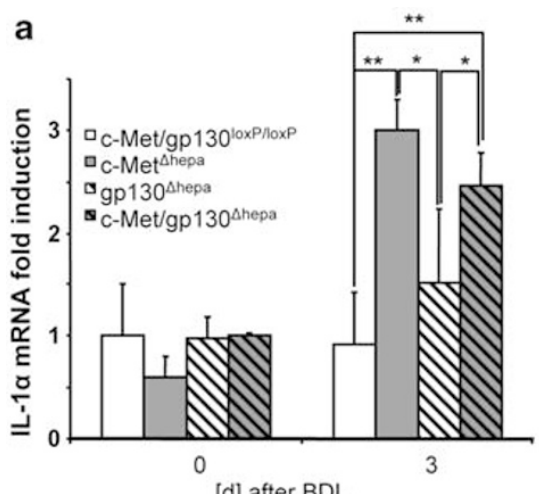

b

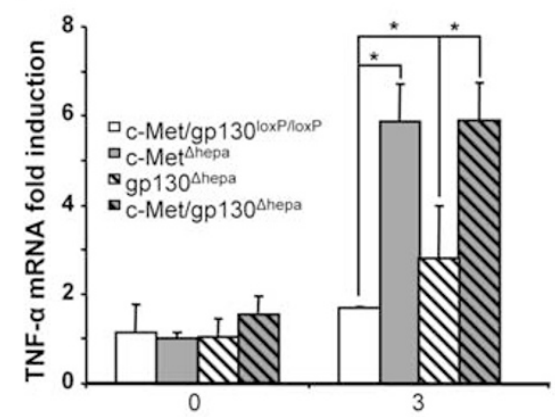

[d] after BDL c

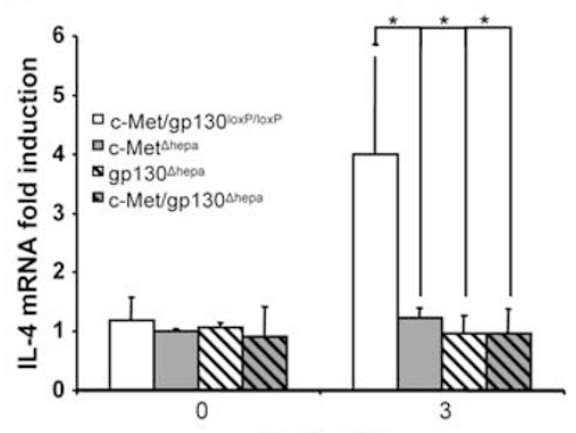

[d] after BDL

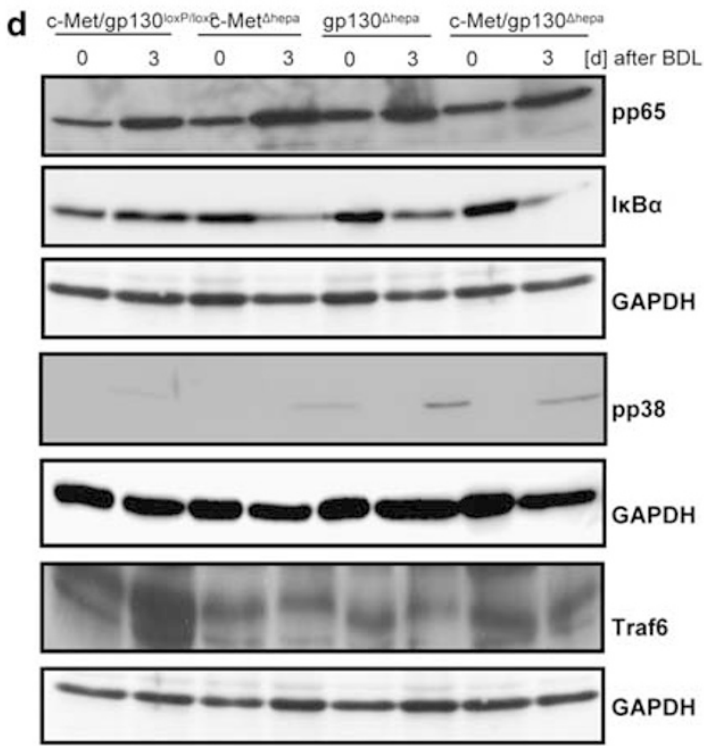

Figure 5 Inflammatory response. Pro-inflammatory and anti-inflammatory cytokine expression was analysed by real-time PCR for, IL-1 $\alpha$ (a), TNF- $\alpha$ (b) and IL-4 (c). Western blot analysis of whole-liver extracts were performed for the transcription factor NF-KB pp65 (d, first panel) and its inhibitor $\mathrm{IkB} \alpha$ (d, second panel), for the activation of p38 MAP kinase (d, fourth panel) and the regulative factor TRAF6 (d, sixth panel). GAPDH analysis was used as a housekeeping gene. ${ }^{*} P<0.05 ;{ }^{* *} P<0.01$; and ${ }^{\#} P<0.001$.

expression of pro-inflammatory cytokines was analysed. We found that IL- $1 \alpha$, TNF- $\alpha$ (Figures $5 \mathrm{a}$ and $\mathrm{b}$ ) and IL-6 (Figure $6 \mathrm{a}$ ) were significantly stronger induced in $\mathrm{c}-\mathrm{Met}^{\text {Ahepa }}$, gp130 ${ }^{\text {Ahepa }}$ and c-Met/gp130 1 hepa mice compared with control mice.

Normal homeostasis after tissue injury is balanced by the regulation of pro- and anti-inflammatory factors. To limit tissue damage anti-inflammatory cytokines like IL-4 are activated. IL-4, known to have an important role in the resolution of acute tissue injury and the termination of the inflammatory response, was strongly induced in c-Met/ gp $130^{\text {loxP/loxp }}$ controls 3 days after BDL. In contrast, this regulation was not evident in all the three conditional knockout groups (Figure 5c). A stronger pro-inflammatory response as shown in the knockout strains after BDL might also have an impact on the downstream pathways after receptor activation. We thus analysed activation of transcription factors mediating the intracellular response. NF- $\kappa \mathrm{B}-\mathrm{a}$ downstream target of TNF- $\alpha$ signalling-was investigated. Western blot analysis showed stronger NF- $\mathrm{\kappa B}$ phosphoryla- tion in c-Met ${ }^{\Delta \text { hepa }}$, gp $130^{\Delta \text { hepa }}$ and c-Met/gp130 ${ }^{\Delta \text { hepa }}$ mice in comparison with c-Met/gp130 ${ }^{\operatorname{loxP} / \text { loxp }}$ mice (Figure 5d, first panel). IkB $\alpha$ - which controls NF- $\kappa \mathrm{B}$ activation in a negative feedback loop-was accordingly more degraded in livers of

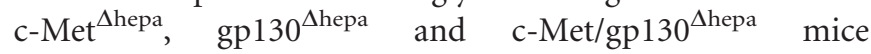
(Figure $5 \mathrm{~d}$, second panel). TNF- $\alpha$-dependent p38 MAP kinase was stronger phosphorylated in c-Met ${ }^{\Delta \text { hepa }}$, gp $130^{\Delta \text { hepa }}$ and c-Met/gp $130^{\Delta \text { hepa }}$ mice as compared with c-Met/ gp130 $0^{\text {loxP/loxP }}$ control mice (Figure $5 d$, fourth panel). Protein expression analysis of the TAK1 adaptor molecule TRAF6-a component of the TLR4 signalling pathway-showed a diminished expression of this factor in mice lacking either hepatic c-Met or gp130 signalling, whereas control mice were able to activate TRAF6 (Figure 5d, sixth panel).

\section{The Acute Phase Response is Regulated Independently by Both gp130 and c-Met}

Finally, we investigated the APR, a major component of the innate immune response that gets activated during liver in- 


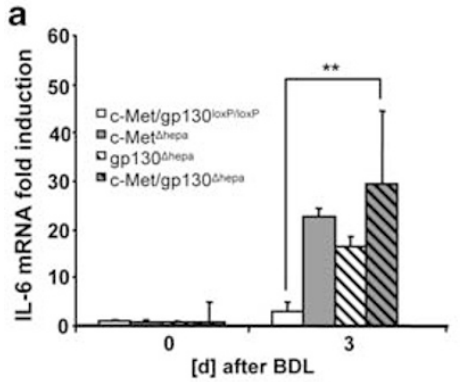

b

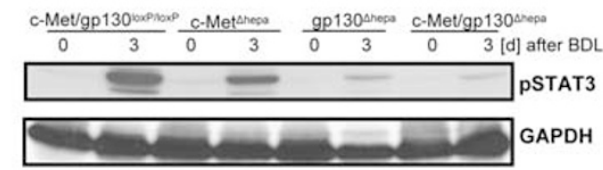

d
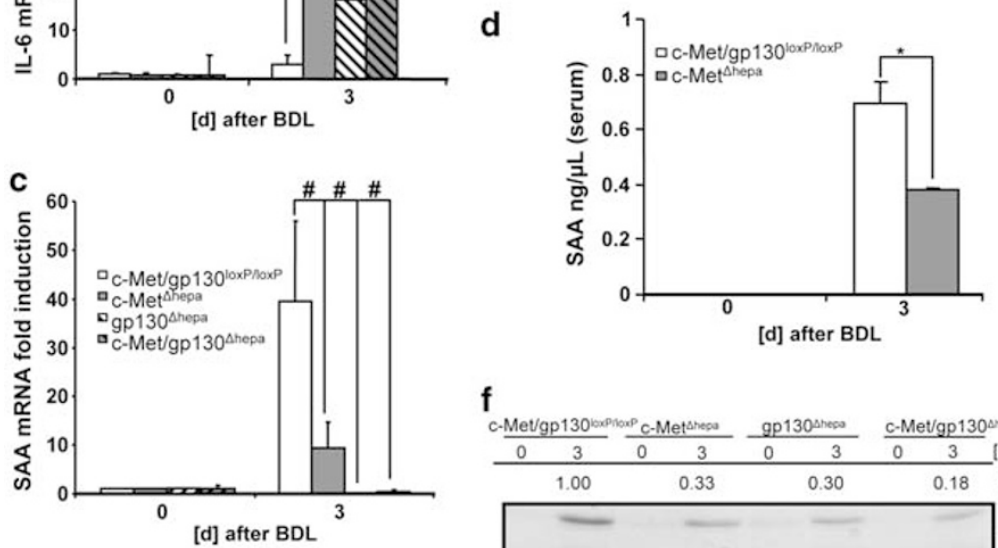

[d] after BDL

f
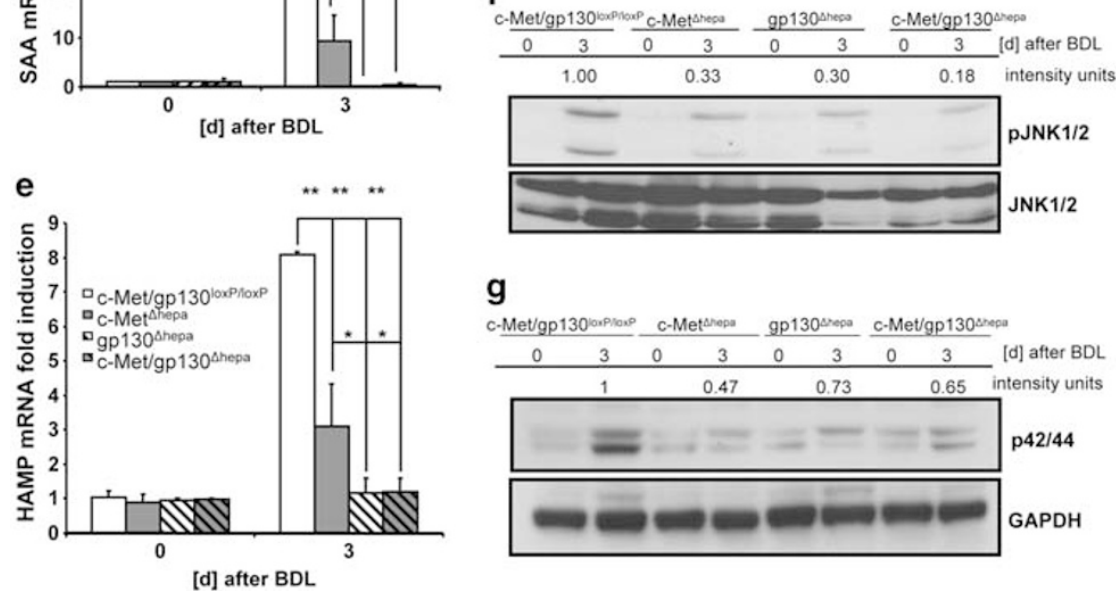

g

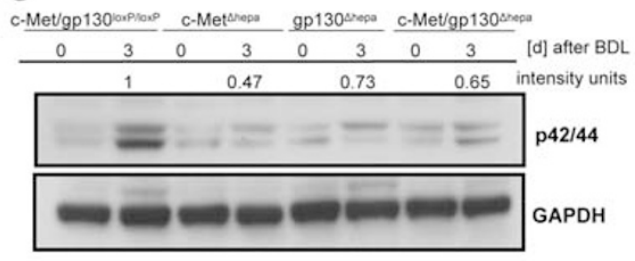

Figure 6 Molecular dissection of the APR. IL-6 was measured by real-time PCR as one of the most critical factors and initiators of the APR (a). Western blot analysis was performed to investigate the activation status STAT3 after BDL (b) by using a STAT3-Y705-phosphorylation-specific antibody. Relative amounts of protein are compared with GAPDH as a housekeeping gene (b, lower panel). Expression analysis of the STAT3 target gene SAA was performed by real-time PCR (c). SAA protein was quantified from the serum c-Met ${ }^{\text {thepa }}$ mice by ELISA (d). RT-PCR analysis was also performed for Hepcidin (e). The activation of JNK1/2 (f) and p42/44 MAPK (g) was analysed by western blots. ${ }^{*} P<0.05 ;{ }^{*} P<0.01 ;$ and ${ }^{\#} P<0.001$.

jury. The transcription factor STAT3 acts as the main regulator of APR-related gene expression. Western blot analysis of total liver extracts displayed strong STAT3 phosphorylation in control mice. Interestingly, c-Met ${ }^{\text {hhepa }}$ mice showed diminished STAT3 phosphorylation despite higher IL-6 expression (Figure 6a). STAT3 phosphorylation was almost completely abolished in gp130 $0^{\Delta \text { hepa }}$ and c-Met/gp $130^{\Delta \text { hepa }}$ mice (Figure 6b). The STAT3-dependent APR gene SAA was regulated concordantly (Figures $6 \mathrm{c}$ and d). HAMP (Hepcidin), which also serves as an $A P R$ gene, was analysed by realtime PCR (Figure 6e) and showed an almost similar expression pattern as found for SAA. This dependency of the SAA and Hepcidin regulation on HGF-mediated signalling could be confirmed by gene array analysis. ${ }^{15}$ The finding of

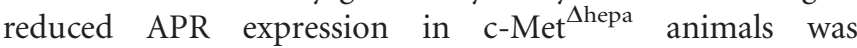
confirmed on the protein level. Reduced SAA levels were evident in serum (Figure 6d) of bile duct-ligated c-Met ${ }^{\text {thepa }}$ mice compared with controls.
Finally, we analysed the activation of p42/44 MAPK and JNK1/2 after BDL. Phosphorylation of both kinases was impaired if either c-Met or gp130 are lacking as shown by western blot (Figures $6 \mathrm{f}$ and g). To exclude unspecific cholestasis-related effects triggered by BDL-dependent injury, we also challenged control and knockout strains with LPS. Notably, after LPS stimulation c-Met ${ }^{\text {thepa }}$ mice showed reduced STAT3 phosphorylation and lower expression of SAA (Supplementary Figures $4 \mathrm{a}$ and $\mathrm{b}$ ).

\section{DISCUSSION}

Cholestasis-associated hepatitis and hepatic failure in human are often complicated by increased susceptibility to toxins and therefore associated with infectious complications. A better understanding of cholestasis-related pathogenetic factors is thus important to develop novel strategies to therapeutically target these molecular mechanisms. 
Previous studies demonstrated that besides inflammatory cytokines (IL- $6^{13}$ and TNF- $\alpha^{20}$ ) also the growth factor $\mathrm{HGF}^{14,15,21}$ was upregulated during cholestatic liver injury. Moreover, both IL-6/gp130 and HGF/c-Met controlled pathways were independently shown to limit the progression of experimentally induced cholestasis ${ }^{15,22}$ in animal models. Here, we demonstrate that deletion of both gp130 and c-Met signalling in hepatocytes leads to an additive degree of parenchymal and biliary tissue injury (Figures $1 b, c$ and $2 c$ ) and a dysregulation of the hepatic innate immune response. The most prominent phenotype of the bile duct-ligated knockout animals was the higher bacterial burden found in their blood and livers, which was associated with severe differences in mortality rates. Thus, we tested the hypothesis, if the cross talk between hepatocellular c-Met and gp130-dependent signalling is crucial in regulating the hepatic antibacterial defence in vivo.

The relevance of bacterial translocation via the gut in general and the potential role of bacterial toxins during cholestasis were highlighted previously. Seki et al demonstrated that intestinal microbes are involved in triggering progression of liver fibrosis in mice during cholestatic liver injury through a TLR4-dependent mechanism. Here, LPS binds LBP and its co-receptor CD14, which form a complex with TLR4 and subsequently activate downstream hepatic anti-microbial pathways. Our present data demonstrate that c-Met and gp130-dependent signalling differentially regulates the expression of receptors leading to the activation of TLR4dependent pathways.

Gp130 deficiency resulted in reduced expression of LBP while the LBP co-receptor CD14 was upregulated. This finding had no impact on the invasion of bacteria into the liver, however, (Figure 2b) it was associated with more pronounced necrosis and early death. In contrast, CD14 was not increased in mice lacking c-Met expression either alone or in combination with gp130, a finding which is supported by our previously performed gene array ${ }^{15}$ (Supplementary Table 1).

Dysregulation of the LBP/CD14 complex is thought to be relevant during progression of chronic cholestatic liver injury as gut sterilisation slows the development of liver fibrosis. ${ }^{1}$ In addition, CD14 polymorphisms are associated with increased susceptibility during the progression of cholestatic liver disease. ${ }^{23}$ As LBP is involved in controlling the innate immune response and also hepatic tissue reconstitution ${ }^{24}$ the lack of its regulation in gp130-deleted mice very likely contributes to the severe phenotype found after BDL.

MyD88, a downstream molecule, involved in TLR4 signalling is essential to mediate survival during bacterial infections. ${ }^{1,25}$ Interestingly, the expression of MyD88 was not increased in gp $130^{\Delta \text { hepa }}$ and c-Met/gp $130^{\Delta \text { hepa }}$ mice, as one would have expected in relation to the bacterial load found in those mice. However, a gp130-dependent gene expression of MyD88 in hepatocytes was previously shown. ${ }^{26}$ In contrast, MyD88 expression was induced in c-Met ${ }^{\Delta \text { hepa }}$ mice, which might explain why these mice did not suffer from early mortality despite their significantly higher hepatic bacterial load compared with wt animals. MyD88 is also involved in TLR2, 4 and IL-1 receptor signalling and thus this observation suggest that activation of these pathways is impaired in those mice (Figures $4 \mathrm{a}$ and $\mathrm{d}$ ).

TRAF6 is located further downstream of MyD88 and thus is one of the gatekeepers for MyD88-induced signalling. TRAF6 is only upregulated in control mice after BDL, whereas it remained unchanged in mice lacking either c-Met or gp130. As TRAF6 is part of the MyD88-IRAK complex it is involved in inducing NF- $\mathrm{BB}$ via TAK1 and the hepatic immune response. ${ }^{27}$ The relevance of this observation is strengthened by the finding of reduced IRAK4 mRNA and protein expression in these mice, which is an important regulatory kinase of this pathway. Furthermore, we would suggest a more critical role of STAT proteins in the regulation of IRAK4 gene expression, because STAT3 activation is significantly reduced by either c-Met or gp130pathway deficiency. In parallel to IRAK4 also TIRAP, another TLR4 adaptor molecule involved in LPS-related TLRs signalling ${ }^{4}$ was only induced in control mice further supporting the finding that c-Met or gp130 expression is essential in directly regulating the antibacterial response in hepatocytes.

The p38 MAPK pathway can be activated by different upstream kinases including TRAF6. However, in c-Met ${ }^{\Delta \text { hepa }}$, gp130 $10^{\Delta \text { hepa }}$ and $\mathrm{c}$-Met/gp130 $0^{\Delta \text { hepa }}$ mice a stronger inflammatory response, eg, higher TNF, IL- $1 \alpha$ and IL-6 was found. This observation explains why despite lower TRAF6 expression the knockout animals showed stronger p38 induction as these mediators can activate p38 independent of TRAF6. The change in the pro-inflammatory response is likely triggered by the higher bacterial load. The need for an ongoing inflammatory reaction in the knockout strains blocks the activation of an anti-inflammatory cascade and therefore low IL-4 expression was evident in these livers. The stronger degree of liver injury in the receptor-deleted mice can also be related to the reduced activation of JNK and p42/44 MAPK, as both were found to be less phosphorylated (Figures $6 \mathrm{f}$ and $\mathrm{g}$ ). Previous analysis of JNK described especially for JNK1 a protective role ${ }^{28}$ in hepatocytes. Thus, the missing activation of both phosphokinases might explain the increased tissue damage. Here, further research is necessary to define the role of JNK in individual cell types, as it is proven to be an important regulator of liver injury.

These mechanisms trigger stronger infiltration of immune cells into the liver. They are in term able to produce so-called AMPs, which contribute to the antibacterial defense. The main sources of AMPs-such as the CRAMP-are neutrophils. Neutrophils are also the most important cellular effectors recruited to the site of inflammation and injury to resolve organ damage. ${ }^{29}$ In our animals, we found a direct correlation between the number of infiltrating neutrophils 
and CRAMP expression. CRAMP was also induced by LPS in primary hepatocytes (Supplementary Figure 2a), although the overall expression level here is lower than that in immune cells. At present, hepatocytes have not been described as producers of AMPs. Thus, their contribution to the innate immune and specifically to the antibacterial response might have been underestimated so far.

The consecutive analysis of the innate immune response evidenced a changed expression of hepatic intracellular pathogen recognition receptors. Expression of NOD-1-an essential factor mediating the recognition of Gram-negative bacteria and trigger for the innate immune response in epithelial and immune cells ${ }^{30}$-was somewhat unexpectedly reduced in gp $130^{\Delta \text { hepa }}$ mice. Nlrp3 was concordantly mostly induced in $\mathrm{c}-\mathrm{Met}^{\mathrm{\Delta hepa}}$ mice, in contrast to gp130-deleted mice. The gp130 restricted expression of those members of the inflammasome complex ${ }^{31}$ thus correlated with survival of bile duct-ligated mice. But, further research is necessary to better differentiate between individual cell types, which contribute to the expression of the components of the inflammasome complex. Here, gp130-deficient mice might represent a valuable tool for future analysis. This imbalance in the inflammasome complex can also explain the higher number of immune cells recruited to the livers of $\mathrm{c}-M e t^{\Delta \text { hepa }}, \mathrm{gp} 130^{\Delta \text { hepa }}$ and $\mathrm{c}$-Met/gp130 ${ }^{\Delta \text { hepa }}$ mice (see Figures $1 \mathrm{~b}$ and $\mathrm{d}$ ).

Our finding of increased mortality due to the bacterial load was further supported by investigating a second unspecific antibacterial response system of the liver-the APR. In agreement with our earlier results, regulation of APR was completely blocked in gp $130^{\text {thepa }}$ mice as evidenced by blunted STAT3 phosphorylation and expression of STAT3dependent genes, SAA and Hepcidine. However, also in ${\mathrm{c}-M e t^{\text {thepa }}}$ mice the induction of the APR was significantly reduced. These findings are supported by our earlier gene array analysis and thus contribute to the higher bacterial burden found in these animals after BDL.

In summary, our observation of increased tissue damage after BDL in $\mathrm{c}-\mathrm{Met}^{\Delta \text { hepa }}$ and higher early lethality in gp $130^{\text {Ahepa }}$ and c-Met/gp $130^{\Delta \text { hepa }}$ mice can be attributed to several possible mechanisms. First, the impaired antibacterial response results in increased bacterial burden. Especially in gp $130^{\Delta \text { hepa }}$ and $\mathrm{c}$-Met/gp $130^{\Delta \text { hepa }}$ a correct regulation of members of the innate immune response is impaired, which leads to insufficient TLR4- and IL-1-induced signalling and earlier death. Second, higher bacterial load triggers a stronger pro-inflammatory response, eg, TNF- $\alpha$, which induces proinflammatory and pro-apoptotic/necroptotic pathways, including bile duct remodelling. In addition, the reduced APR in c-Met and especially gp130-deficient mice contributes to a significantly higher degree of liver damage.

Supplementary Information accompanies the paper on the Laboratory Investigation website (http://www.laboratoryinvestigation.org)

\section{ACKNOWLEDGEMENTS}

This study was supported by the following grant: K L Streetz: supported by a grant from the Interdisciplinary Centre for Clinical Research BIOMAT within the faculty of Medicine at the RWTH Aachen University (IZKF-E4) and DFG STR 661/4-1-1.

\section{DISCLOSURE/CONFLICT OF INTEREST}

The authors declare no conflict of interest.

1. Seki E, De Minicis S, Osterreicher CH, et al. TLR4 enhances TGF-beta signaling and hepatic fibrosis. Nat Med 2007;13:1324-1332.

2. Schumann RR, Leong SR, Flaggs GW, et al. Structure and function of lipopolysaccharide binding protein. Science 1990;249:1429-1431.

3. Tobias PS, Soldau K, Gegner JA, et al. Lipopolysaccharide binding protein-mediated complexation of lipopolysaccharide with soluble CD14. J Biol Chem 1995;270:10482-10488.

4. Horng T, Barton GM, Medzhitov R. TIRAP an adapter molecule in the Toll signaling pathway. Nat Immunol 2001;2:835-841.

5. Dunne A, Ejdeback M, Ludidi PL, et al. Structural complementarity of Toll/interleukin-1 receptor domains in Toll-like receptors and the adaptors Mal and MyD88. J Biol Chem 2003;278:41443-41451.

6. Li S, Strelow A, Fontana EJ, et al. IRAK-4: a novel member of the IRAK family with the properties of an IRAK-kinase. Proc Natl Acad Sci USA 2002;99:5567-5572.

7. Girardin SE, Boneca IG, Carneiro LA, et al. Nod1 detects a unique muropeptide from gram-negative bacterial peptidoglycan. Science 2003;300:1584-1587.

8. Kanneganti TD, Lamkanfi M, Nunez G.. Intracellular NOD-like receptors in host defense and disease. Immunity 2007;27:549-559.

9. Gabay JE, Scott RW, Campanelli D, et al. Antibiotic proteins of human polymorphonuclear leukocytes. Proc Natl Acad Sci USA 1989;86: 5610-5614.

10. Cressman DE, Greenbaum LE, DeAngelis RA, et al. Liver failure and defective hepatocyte regeneration in interleukin-6-deficient mice. Science 1996;274:1379-1383.

11. Streetz KL, Wustefeld T, Klein C, et al. Lack of gp130 expression in hepatocytes promotes liver injury. Gastroenterology 2003;125: 532-543.

12. Sander LE, Sackett SD, Dierssen U, et al. Hepatic acute-phase proteins control innate immune responses during infection by promoting myeloid-derived suppressor cell function. J Exp Med, 207: 1453-1464.

13. Wuestefeld T, Klein C, Streetz KL, et al. Interleukin-6/glycoprotein 130dependent pathways are protective during liver regeneration. J Biol Chem 2003;278:11281-11288.

14. Borowiak M, Garratt AN, Wustefeld T, et al. Met provides essential signals for liver regeneration. Proc Natl Acad Sci USA 2004;101: 10608-10613.

15. Giebeler A, Boekschoten MV, Klein C, et al. c-Met confers protection against chronic liver tissue damage and fibrosis progression after bile duct ligation in mice. Gastroenterology 2009;137:297-308, e291294.

16. Betz UA, Bloch $W$, van den Broek $M$, et al. Postnatally induced inactivation of gp130 in mice results in neurological, cardiac, hematopoietic, immunological, hepatic, and pulmonary defects J Exp Med 1998;188:1955-1965.

17. Wuestefeld $\mathrm{T}$, Klein $\mathrm{C}$, Streetz KL, et al. Lack of gp130 expression results in more bacterial infection and higher mortality during chronic cholestasis in mice. Hepatology 2005;42:1082-1090.

18. Fausto $\mathrm{N}$. Involvement of the innate immune system in liver regeneration and injury. J Hepatol 2006;45:347-349.

19. Fausto N, Laird AD, Webber EM. Liver regeneration. 2. Role of growth factors and cytokines in hepatic regeneration. FASEB J 1995;9: 1527-1536.

20. Yang YY, Liu H, Nam SW, et al. Mechanisms of TNFalpha-induced cardiac dysfunction in cholestatic bile duct-ligated mice: interaction between TNFalpha and endocannabinoids. J Hepatol 2010;53: 298-306.

21. Huh CG, Factor VM, Sanchez A, et al. Hepatocyte growth factor/c-met signaling pathway is required for efficient liver regeneration and repair. Proc Natl Acad Sci USA 2004;101:4477-4482. 
22. Plum W, Tschaharganeh DF, Kroy DC, et al. Lack of glycoprotein 130 signal transducer and activator of transcription 3-mediated signaling in hepatocytes enhances chronic liver injury and fibrosis progression in a model of sclerosing cholangitis. Am J Pathol, 176: 2236-2246.

23. Shih $\mathrm{HH}$, Lin TM, Chuang JH, et al. Promoter polymorphism of the CD14 endotoxin receptor gene is associated with biliary atresia and idiopathic neonatal cholestasis. Pediatrics 2005;116:437-441.

24. Lehnert M, Uehara T, Bradford BU, et al. Lipopolysaccharide-binding protein modulates hepatic damage and the inflammatory response after hemorrhagic shock and resuscitation. Am J Physiol Gastrointest Liver Physiol 2006;291:G456-463.

25. Kawai T, Adachi O, Ogawa T, et al. Unresponsiveness of MyD88deficient mice to endotoxin. Immunity 1999;11:115-122.
26. Klein C, Wustefeld T, Assmus U, et al. The IL-6-gp130-STAT3 pathway in hepatocytes triggers liver protection in T cell-mediated liver injury J Clin Invest 2005:115:860-869.

27. Beutler B. Inferences, questions and possibilities in Toll-like receptor signalling. Nature 2004;430:257-263.

28. Kluwe J, Pradere JP, Gwak GY, et al. Modulation of hepatic fibrosis by c-Jun-N-terminal kinase inhibition. Gastroenterology, 138:347-359.

29. Welbourn CR, Young Y. Endotoxin, septic shock and acute lung injury: neutrophils, macrophages and inflammatory mediators. Br J Surg 1992;79:998-1003.

30. Clarke TB, Davis KM, Lysenko ES, et al. Recognition of peptidoglycan from the microbiota by Nod1 enhances systemic innate immunity Nat Med, 16:228-231.

31. Schroder K, Tschopp J. The inflammasomes. Cell, 140:821-832. 